\title{
ALTERAÇÕES ANTRÓPICAS E REPERCUSSÕES NA DINÂMICA DO RIO JACARÉ-PEPIRA (SP)
}

\author{
Everton Vinicius Valezio ${ }^{(a)}$, Archimedes Perez Filho ${ }^{(b)}$ \\ (a) Departamento de Geografia/Instituto de Geociências, Unicamp, evertonvalezio@ige.unicamp.br \\ (b) Departamento de Geografia/Instituto de Geociências, Unicamp, archi@ige.unicamp.br
}

Eixo: Uso e ocupação das terras e legislação ambiental

\begin{abstract}
Resumo
A ação efetiva do homem como agente potencializador de processos o coloca como novo fator alogênico de alteração da paisagem. Ao modificar condições de fluxo e aporte de sedimentos, a ação antrópica influencia na morfologia dos canais fluviais. Desta forma, o estudo proposto interpreta as modificações da morfologia do rio Jacaré-Pepira (SP), sobretudo no baixo curso, motivado pela instalação da usina hidrelétrica de Ibitinga e pela formação de novo nível de base local, e às modificações no uso da terra ao longo da bacia. Tais transformações foram identificadas por imagens não orbitais (1:25.000) datadas de 1962 e orbitais (Rapideye) de 2012, a fim de comparar esses dois momentos. Constataram-se mecanismos de modificação de meandros mais significativos nos segmentos influenciados diretamente pela mudança de nível de base. Além disso, foi possível observar a ampliação de cultivos agrícolas sobre áreas vegetadas e com pouca aplicação agrícola, reiterando o homem como agente geomorfológico.
\end{abstract}

Palavras chave: Morfodinâmica; Uso da terra; Alteração antrópica; Canal fluvial.

\section{Introdução}

A intensificação dos processos antrópicos de alteração do uso e ocupação das terras, via urbanização, modificação de cultivares agrícolas e obras civis, tem promovido substanciais modificações nos regimes fluviais, colocando o homem como potencializador dos processos de erosão, transporte e deposição.

Tais processos têm repercussões diretas nos canais fluviais, alterando sua morfologia ao recepcionarem, enquanto níveis de base locais, os fluxos superficiais e subsuperficiais presentes na área da bacia hidrográfica. A contribuição antrópica na maior entrada de matéria e energia e, consequentemente, na menor capacidade de recepção dos fluxos pelos corpos hídricos, é largamente debatida, pelas modificicações no uso da terra (COSTA et al., 2003; VALEZIO; PEREZ FILHO, 2015; ZANATTA et al., 2015) e na ação direta pela construção civil - canalização, barramento, sistema de galerias pluviais (MAGILLIGAN; NISLOW, 2005; PETTS; GURNELL，2005; GRAF，2006; GREGORY，2006; POLLOCK et al., 2007), evidenciando o papel cada vez mais ativo do homem na resposta dos sistemas físicos. 
Os efeitos hidrológicos ocasionados pela inserção do homem no sistema se dão na modificação de tempo, magnitude e frequência dos fluxos de alta e baixa frequência e nos demais efeitos geomorfológicos advindos dessa relação, o que inclui as singularidades de cada sistema fluvial (POWER et al., 1996).

Asssociada a esses fatores, a bacia hidrográfica do rio Jacaré-Pepira (SP) tem se mostrado importante para a observação de processos de modificação do canal fluvial frente às variáveis físicas, sobretudo no que tange a ação antrópica. Essas intervenções, caracterizadas pela construção de barramentos e pela modificação do uso da terra, somadas ainda à ação natural dos rios em se modificarem, propiciaram nova configuração do rio Jacaré-Pepira nos últimos 50 anos.

Dentro desse quadro, seccionamos diversas ações dessa natureza promovidas na área da bacia do rio Jacaré-Pepira e suas repercussões no canal fluvial principal, capazes incorporar nova dinâmica hidrossedimentar e propiciar condições para alterações morfológicas do rio.

\section{Materiais e Método}

Localizada na porção central do estado de São Paulo, a bacia hidrográfica do rio Jacaré-Pepira possui uma área de drenagem aproximada de $2573 \mathrm{~km}^{2}$, perpassando 13 municípios ${ }^{1}$, tendo como altitude máxima os 1020 metros nas cabeceiras e a mais baixa os 405 metros próximos à foz. Seu curso principal transcorre longitudinalmente pouco mais de 207 quilômetros, das cabeceiras na Serra de São Pedro à foz no médio rio Tietê, junto ao lago formado pela barragem da usina hidrelétrica de Ibitinga. Já em área de reverso da cuesta arenito-basáltica, o rio Jacaré-Pepira ruma para porções centrais do Planalto Ocidental Paulista (Figura 1).

Segundo IPT (2003), a precipitação média para o rio Jacaré-Pepira é de 1395 mm anuais para a alta e 1290 $\mathrm{mm}$ anuais para a média e baixa bacia hidrográfica. A pluviosidade e a temperatura média, superior a 22 ${ }^{\circ} \mathrm{C}$ nos meses mais quentes e pouco inferior a $18{ }^{\circ} \mathrm{C}$ no inverno (COSTA, 2005), colaboram para a presença da vegetação natural e para a atividade agrícola ao longo da bacia. Tomam destaque a vegetação higrófila e hidrófila, associada aos diques marginais, às planícies de inundação e aos terraços fluviais; além da Floresta Estacional Semidecidual e da Floresta Ombrófila, distribuídas principalmente nos trechos

\footnotetext{
${ }^{1}$ São Pedro, Itirapina, Torrinha, Brotas, Dois Córregos, Ribeirão Bonito, Dourado, Jaú, Bocaina, Boa Esperança do Sul, Bariri, Itaju e Ibitinga.
} 
iniciais do reverso das cuestas, nas encostas e topos dos morros testemunhos e dispersas ao longo da bacia, entremeadas às atividades agrícolas.

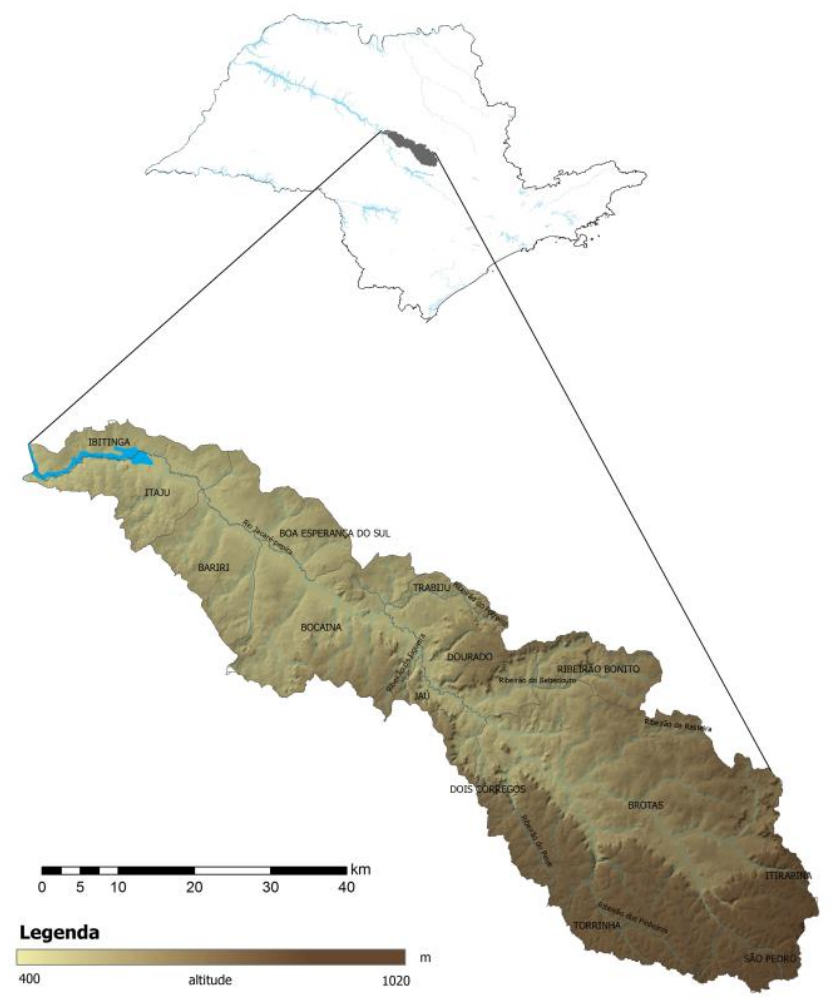

Figura 1: Localização da bacia hidrográfica do rio Jacaré-Pepira (SP). Elaboração: Éverton V. Valezio.

Aliada às características climáticas e vegetacionais, a litologia da área favorece também o cultivo agrícola, pelo processo contínuo de alteração das rochas e gênese de solos, propício às atividades agrícolas. As formações Piramboia, Botucatu, Serra Geral e Itaqueri (DAEE/UNESP, 1982) formam o arcabouço geológico, sustentando o relevo local, dando origem aos solos locais e, pelos processos supérgenos e pela ação antrópica cada vez mais ativa, fornecem material sedimentar para mobilização nos cursos fluviais.

A atividade agropecuária tem se intensificado nessas áreas, com destaque para a ampliação da citricultura, da silvicultura e do cultivo de cana-de-açúcar, cujos reflexos se abatem sobre as modificações de uso da terra e na ampliação dessas áreas nas proximidades dos cursos fluviais.

Para este trabalho, foram selecionadas imagens não orbitais datadas de 1962 e imagens orbitais de 2011, 2012 e $2013^{2}$, propiciando uma análise comparativa de aproximadamente 50 anos. As primeiras, em escala aproximada de 1:25.000, foram adquiridas no Instituto Agronômico de Campinas (IAC). Já as segundas

${ }^{2}$ Imagens de 2011 e 2013 foram adicionadas pela menor quantidade de ruído e pela presença de nuvens na imagem de 2012, em determinadas partes da bacia. 
correspondentes a imagens multiespectrais do Sistema Rapideye, com resolução especial de 6,5 metros e tamanho de pixel de 5 metros (BLACKBRIDGE, 2015), foram adquiridas gratuitamente via website $<$ http://geocatalogo.ibama.gov.br>.

Ambos os produtos foram utilizados para a restituição do canal fluvial e de suas formas associadas para os períodos supracitados, ligando-os às possíveis influências antrópicas e à repercussão espacial das modificações na determinação das alterações presentes no rio Jacaré-Pepira.

\section{Resultados e Discussão}

Os resultados obtidos pela integração das metodologias apontam para respostas mais proeminentes do rio Jacaré-Pepira nas áreas em que seu curso meandrante é afogado pelas águas do reservatório da usina hidrelétrica de Ibitinga.

Esta usina passou a operar em 1969, após 5 anos de construção (www.aestiete.com.br), inserindo-se como novo nível de base local. A influência demarcada no curso do Jacaré-Pepira se efetiva pelo afogamento da foz e pela expansão do lago da represa para a bacia do rio Jacaré-Pepira. As fotografias aéreas datadas de 1962 - pretéritas à instalação da barragem - e as imagens de satélite de 2012 apontam justamente para a influência deste novo nível na modificação da morfologia do canal estudado (Figura 2).

Ao contrário dos outros dois barramentos não naturais ao longo do curso principal, a usina hidrelétrica de Ibitinga e o lago associado foram fundamentais para alterações na dinâmica do rio. Os outros dois barramentos não foram suficientes para alterar morfologicamente o rio Jacaré-Pepira, pois se encontram em áreas muito a montante, aproveitando-se da já acentuada declividade, do leito basáltico - que limita a divagação lateral - e da baixa vazão nesse ponto do rio. 


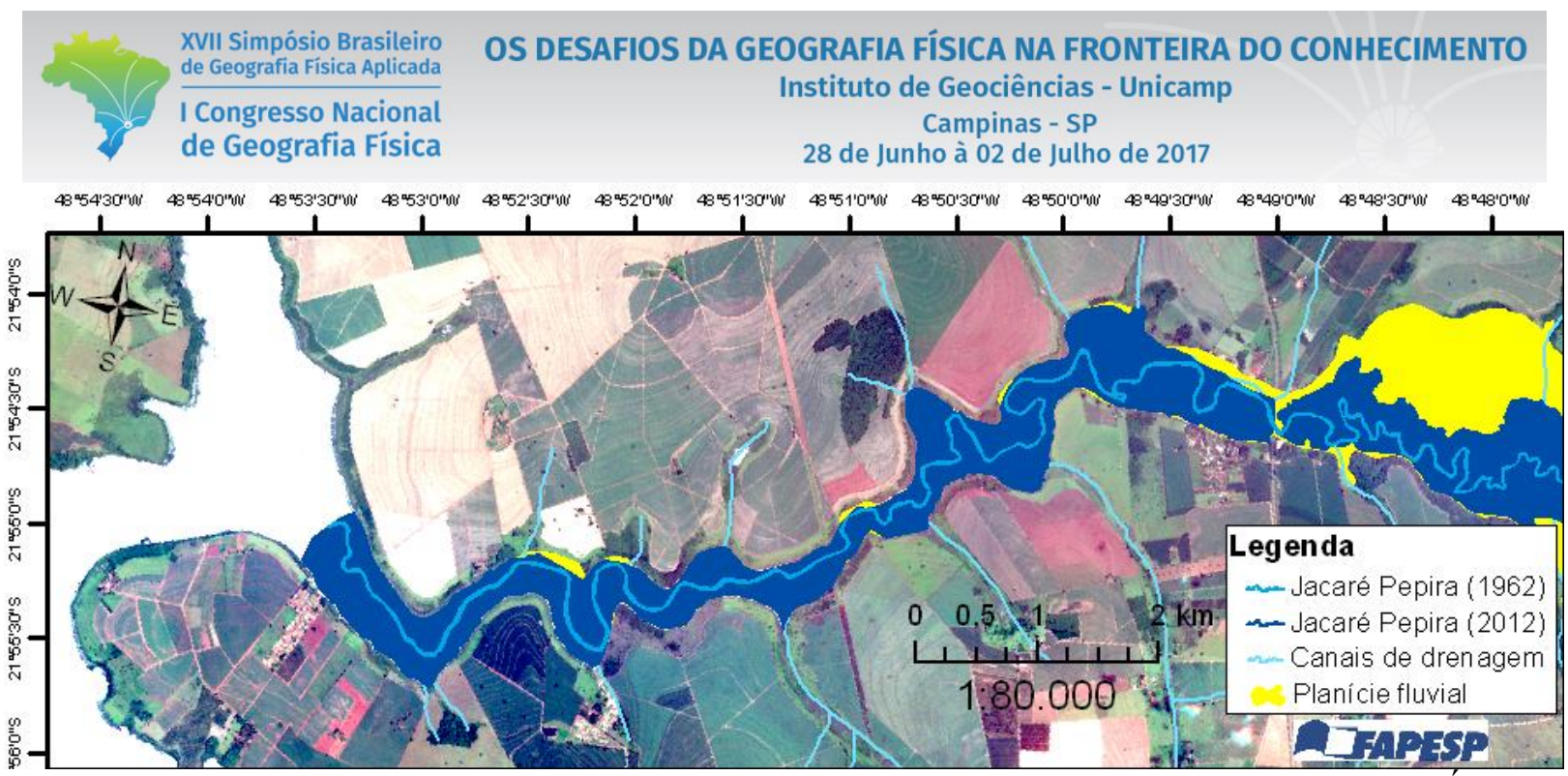

Figura 2: Setor alagado do rio Jacaré-Pepira pelo represamento da usina de Ibitinga. Elaboração: Éverton

\section{Valezio.}

Em áreas em que o rio Jacaré-Pepira se consuma sobre as formações Piramboia e Botucatu, ou com leitos constituintes dos seus próprios depósitos, a tipologia meandrante é o padrão característico. Apesar da presença de mecanismos de modificação constantes nesses segmentos, aquelas mais proeminentes se encontram nos setores de baixo curso, influenciado pelas novas condições impostas pela mudança de nível de base.

Dentre os mecanismos de modificação no setor individualizado (Figura 3) destacam-se rotações, translações, crescimento lateral e principalmente os cutoff's, totalizando 10 cortes de meandro, de 1962 a 2012. Esse mecanismo é destacado pois é bem marcado em rios com mudanças mais proeminentes no balanço sedimentar e de escoamento superficial, buscando o rio um melhor ajuste das variáveis físicas presentes.

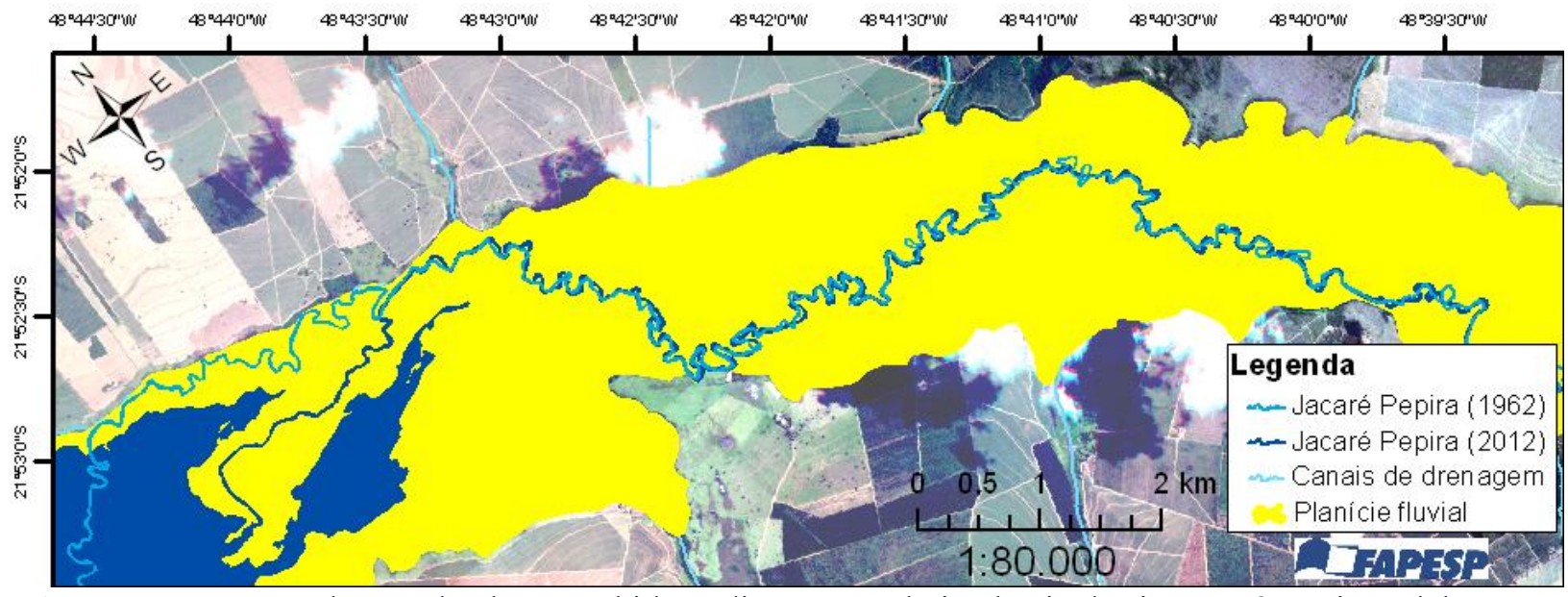

Figura 3: Segmento de grande alteração hidrosedimentar na baixa bacia do rio Jacaré-Pepira. Elaboração: Éverton V. Valezio. 


\section{OS DESAFIOS DA GEOGRAFIA FÍSICA NA FRONTEIRA DO CONHECIMENTO \\ Instituto de Geociências - Unicamp \\ Campinas - SP \\ 28 de Junho à 02 de Julho de 2017}

Outra modificação no balanço sedimentar remete a mudanças no uso e na ocupação das terras na bacia hidrográfica. A atividade do "turismo de aventura", presente de forma efetiva a partir da década de 1990 e intensificada nos anos 2000 (SILVA, 2006) como uma das principais atividades econômicas no alto curso, liga-se a ambientes naturais preservados e influencia na preservação das matas ciliares e das áreas florestadas naturais, muito em função das condições topográficas e da dificuldade de acesso ao uso e à ocupação urbana e de determinados cultivos. Entretanto, mesmo nas áreas dependentes das características do relevo, do clima e do canal fluvial preservado para as atividades turísticas, há pressão cada vez maior pelo avanço dos cultivos de laranja e cana-de-açúcar, sobretudo para as proximidades do rio Jacaré-Pepira e, consequentemente, avançando sobre a vegetação nativa (Figura 4). 


\begin{tabular}{|c|c|}
\hline $\begin{array}{l}\text { XVII Simpósio Brasileiro } \\
\text { de Geografia Fisica Aplicada } \\
\end{array}$ & $\begin{array}{l}\text { OS DESAFIOS DA GEOGRAFIA FÍSICA NA FRONTEIRA DO CONHECIMENTO } \\
\text { Instituto de Geociências - Unicamp }\end{array}$ \\
\hline $\begin{array}{l}\text { I Congresso Nacional } \\
\text { de Geografia Física }\end{array}$ & $\begin{array}{c}\text { Campinas - SP } \\
28 \text { de Junho à } 02 \text { de Julho de } 2017\end{array}$ \\
\hline
\end{tabular}

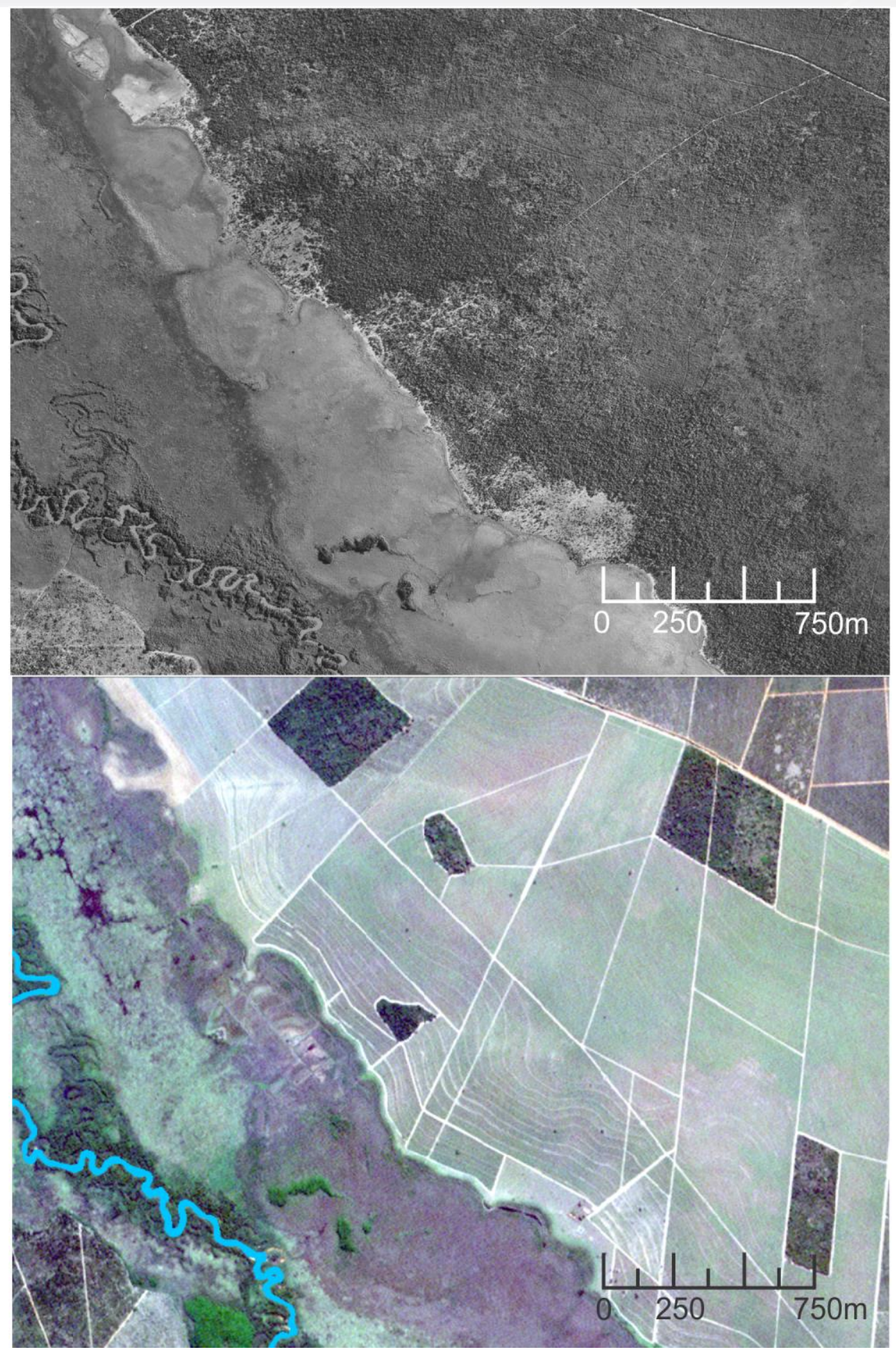

Figura 4: Mudança substancial de uso da terra em porções próximas ao rio Jacaré-Pepira. A fotografia aérea de 1962 (porção superior) retrata vegetação nativa ainda de forma proeminente. A imagem de 2012 (porção inferior) já mostra os diversos talhões seccionados pelo avanço da cultura de cana-de-açúcar. Elaboração: Éverton V. Valezio. 
O substancial crescimento dos cultivos de laranja, eucalipto e de cana-de-açúcar é a principal alteração visualizada nas imagens orbitais e não orbitais no período analisado, substituindo principalmente porções de terra antes ocupados por pastos, cerrado e suas fitofisionomias e por matas de galeria.

Como evidenciado anteriormente, a construção da barragem e a inserção destas como novo patamar, não gerado normalmente por diferença litológica ou ação tectônica, promovem a segmentação dos canais em novos níveis de base locais, influenciando na morfologia do canal fluvial a montante. Em conjunto com os processos ligados a modificações do uso das terras estão os redirecionamentos das atividades econômicas inseridas na bacia hidrográfica, que acarretam também em nova resposta dos sistemas naturais para recepcionar condições de transporte e deposição também distoantes das condições anteriores.

Dessa forma, reiteramos o papel promovido pela instalação da barragem de Ibitinga na maior modificação morfológica do rio Jacaré-Pepira, redinamizando suas formas decorrentes do novo nível de base e, consequentemente, do novo balanço hidrossedimentar. $\mathrm{O}$ avanço dos novos usos, especialmente a citricultura, e o crescimento do cultivo de cana-de-açúcar reconfiguram a paisagem local e alteram os regimes erosivos, deposicionais e de transporte de sedimentos e os fluxos pluviais.

\section{Considerações Finais}

As modificações ocorridas em reduzido espaço temporal mostram como os canais fluviais são sistemas sensíveís às condições submetidas na bacia hidrográfica. $\mathrm{O}$ fator antrópico passa a influenciar diretamente na morfologia dos rios e a acelerar os processos antes determinados pelo regime climático e tectônico.

A metodologia empregada, comparando momentos distintos do mesmo canal fluvial, corroborou para a a associação do homem como agente geomorfológico. O estágio de operação da hidrelétrica e a formação do reservatório são fundamentais na nova dinâmica surgente ao longo dos 50 anos analisados, tendo o rio Jacaré-Pepira respondido ao novo controle de descargas. A alteração constante do uso da terra permite novos estádios de adaptação dos canais fluviais, inclusive com dinâmicas de alteração mais aceleradas quando comparadas a setores com influências mais brandas. O ajustamento dos canais fluviais vai além das novas condições impostas, e a resposta morfológica estimada pela ação antrópica neste trabalho pode se desdobrar pela presença de dados pluviométricos e fluviométricos, que aumentariam os detalhes da alteração, com estimativas quantitativas. Contudo, significativos hiatos temporais e espaciais reduzem consideravelmente estimativas mais precisas no balanço hídrico e de sedimentos e dificultam a precisão de interpretação desses sistemas fluviais complexos. 


\section{Agradecimentos}

Externamos nossos agradecimentos à FAPESP (Fundação de Amparo à Pesquisa do Estado de São Paulo), pela viabilização financeira da pesquisa (Processo n. 2013/24885-1).

\section{Bibliografia}

AESTIETÊ. Usina e eclusas. Disponível em: <http://www.aestiete.com.br/geracao/Paginas/nossasusinas.aspx>, Acesso em: 28 jan. 2017.

BLACKBRIDGE. The RapidEye Red Edge Band 2015. Disponível em: http://www.blackbridge.com/rapideye/upload/Red_Edge_White_Paper.pdf. Acesso em 4 setembro de 2015.

COSTA, A. L. C. de. Estudo de vulnerabilidade à erosão com a aplicação da Equação Universal de Perda de Solo na Alta Bacia Hidrográfica do rio Jacaré-Pepira, utilizando SIG/SPRING. Dissertação (Mestrado), Universidade Estadual Paulista, Rio Claro, 2005.

COSTA, M. H.; BOTTA, A.; CARDILlE, J. A. Effects of large-scale changes in land cover on the discharge of the Tocantins River, Southeastern Amazonia. In: Journal of Hydrology, v. 283, p. 206-217, 2003.

GRAF, W. L. Dowstream hydrologic and geomorphic effects of large dams on American rivers. In: Geomorphology, v. 79, p. 336-360, 2006.

GREGORY, K. J. The human role in changing river channels. In: Geomorphology, v. 79, p. 172-191, 2006.

IPT - INSTITUTO DE PESQUISAS TECNOLÓGICAS. Diagnóstico da situação atual dos recursos hídricos e estabelecimento de diretrizes técnicas para a elaboração do Plano da Bacia Hidrográfica do Tietê/Jacaré. Relatório 40.674, São Paulo, 2003

MAGILLIGAN, F. J.; NISLOW, K. H. Changes in hydrologic regime by dams. In: Geomorphology, v. 71, p. 61-78, 2005.

PETTS, G. E.; GURNELL, A. M. Dams and geomorphology: research progress and future directions. In: Geomorphology, v. 71, p. 27-47, 2005.

POLLOCK, M. M.; BEECHIE, T. J.; JORDAN, C. E. Geomorphic changes upstream of beaver dams in Bridge Creek, an incised stream channel in the interior Columbia River basin, eastern Oregon. In: Earth Surface Processes and Landforms, v. 32, p. 1174-1185, 2007.

POWER, M. E.; DIETRICH, W. E.; FINLAY, J. C. Dams and downstream aquatic biodiversity: potential food web consequences of hydrologic and geomorphic change. In: Environmental Management, v. 20, n. 6 , p. $887-895,1996$.

SILVA, C. A. Análise sistêmica, turismo de natureza e planejamento ambiental em Brotas: proposta metodológica. Tese (Doutorado em Geografia). Instituto de Geociências, Universidade de Campinas, Campinas, 2006.

VALEZIO, E. V.; PEREZ FILHO, A. Dinâmica antrópica do canal fluvial do córrego tucum - Sâo Pedro, Sâo Paulo (Brasil). In: Revista Brasileira de Geomorfologia, v. 16, n. 4, p. 545-557, 2015. 


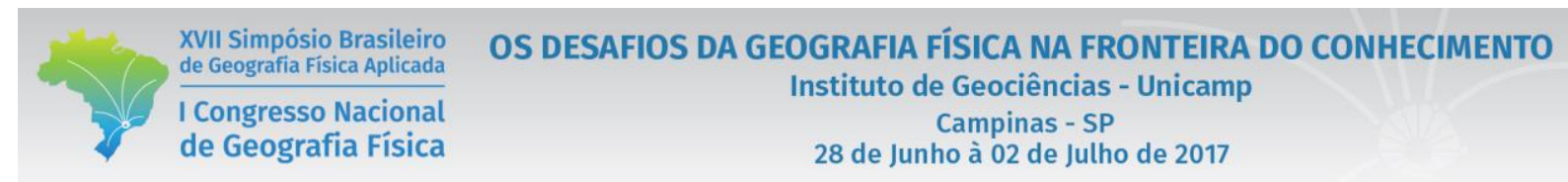

ZANATTA, F. A. S.; LUPINACCI, C. M.; BOIN, M. N. O uso da terra e alterações do relevo na alta bacia do ribeirão areia dourada, Marabá Paulista (SP): um estudo a partir de princípios da antropogeomorfologia. In: Revista Brasileira de Geomorfologia, v. 16, n. 1, p. 3-17, 2015. 